\title{
Impact of bariatric surgery on cancer risk reduction
}

\author{
Debora S. Bruno ${ }^{1}$, Nathan A. Berger ${ }^{1,2}$ \\ ${ }^{1}$ Hematology Oncology Division, Department of Medicine, ${ }^{2}$ Department Biochemistry, Genetics \& Genome Sciences, Case Comprehensive Cancer \\ Center, Case Western Reserve University School of Medicine, Cleveland, OH, USA \\ Contributions: (I) Conception and design: All authors; (II) Administrative support: All authors; (III) Provision of study materials or patients: All \\ authors; (IV) Collection and assembly of data: All authors; (V) Data analysis and interpretation: All authors; (VI) Manuscript writing: All authors; (VII) \\ Final approval of manuscript: All authors. \\ Correspondence to: Nathan A. Berger. Department Biochemistry, Genetics \& Genome Sciences, Case Comprehensive Cancer Center, Case Western \\ Reserve University School of Medicine, 10900 Euclid Avenue, Cleveland, OH 44106, USA. Email: nab@case.edu.
}

\begin{abstract}
Obesity is second only to tobacco as a preventable cause of cancer in the US. By multifactorial and often additive mechanisms, obesity leads to the development and promotion of $40 \%$ of the cancers diagnosed in this country, including post-menopausal breast, endometrial, colorectal, kidney, liver and pancreatic cancers, among others. Though prevention of obesity should be the ultimate goal of thoughtful and effective healthcare practices, it remains a highly prevalent condition, and morbid obesity (BMI $\geq 40 \mathrm{Kg} / \mathrm{m}^{2}$ ) can be refractory to lifestyle interventions in many cases. Currently bariatric surgery is an effective treatment strategy for individuals who suffer from morbid obesity or obesity with associated comorbidities and fail to lose weight under a medically supervised diet and exercise program. The current review addresses seminal studies that have investigated the potential cancer prevention effects of bariatric surgery, demonstrating a positive impact mostly in post-menopausal breast and endometrial cancers. The controversial association between bariatric surgery and increased colorectal cancer (CRC) risk is also recognized and discussed. Finally, while bariatric surgery should not be routinely recommended as a cancer prevention strategy, it has the potential to decrease the risk for certain types of cancers as a collateral beneficial effect.
\end{abstract}

Keywords: Obesity; bariatric surgery; cancer prevention

Submitted Apr 17, 2019. Accepted for publication Aug 26, 2019.

doi: $10.21037 /$ atm.2019.09.26

View this article at: http://dx.doi.org/10.21037/atm.2019.09.26

\section{Introduction}

The obesity pandemic continues to expand on a worldwide basis, bringing with it multiple comorbidities including metabolic syndrome, type 2 diabetes mellitus (T2DM), cardiovascular disease and multiple forms of cancer. The International Agency for Research on Cancer has recently identified 13 malignancies with sufficient evidence for them to be identified as obesity associated cancers (OACs) (1). These OACs include post-menopausal breast, colorectal, kidney, endometrial, thyroid, pancreas, liver, gastric cardia, meningioma, ovary, esophageal adenocarcinoma, gall bladder and myeloma. Several other malignancies including high-risk prostate cancer, especially in African American men (2) non-Hodgkin's lymphoma and melanoma have also been associated with obesity (3).

On a world-wide basis, obesity affects more than 110 million children and 640 million adults $(4,5)$. When combined with its precursor, overweight and obesity are estimated to affect two billion people around the world (6). If current trends continue, the world-wide prevalence of obesity is predicted to reach $18 \%$ in men and exceed $21 \%$ in women by 2025 (4).

The U.S. Center for Disease Control and Prevention (CDC) has indicated $40 \%$ of cancers diagnosed in the US since 2014 were associated with overweight and obesity. Obesity is responsible for $20 \%$ cancer deaths in women and $14 \%$ in men (3). In addition, recent studies indicate that 


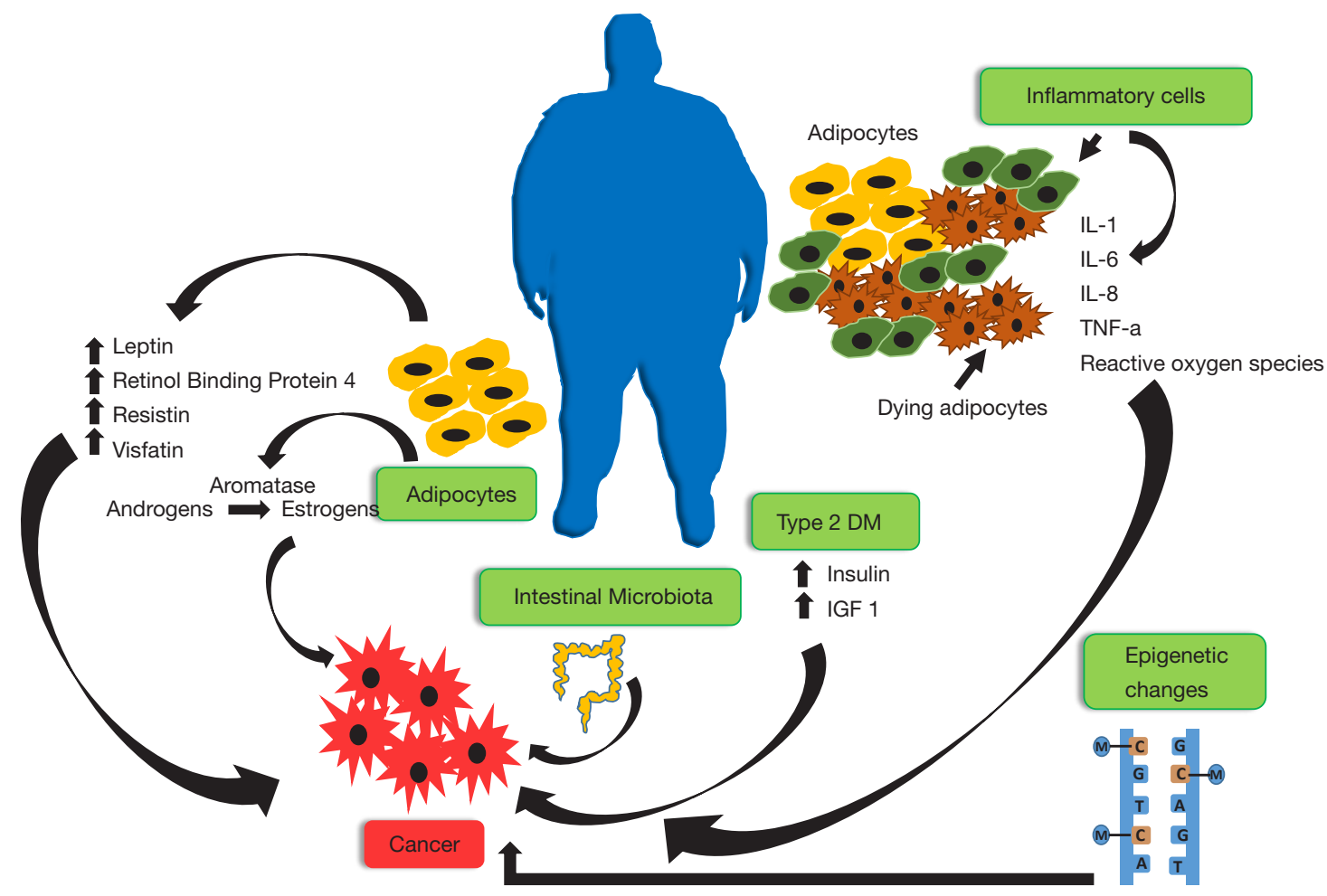

Figure 1 Mechanisms of cancer promotion by obesity.

obesity and obesogenic diets accelerate the development of OACs, contributing to their alarming increase in young adults less than 50 years of age (7) and a shift in cancer burden and financial hardship in patients under $65(8,9)$.

\section{Mechanisms by which obesity promotes cancer}

Obesity promotes and accelerates cancer development and growth by multiple mechanisms $(10,11)$ (Figure 1). While adipose tissue was once considered to simply provide storage for energy rich lipid reserves, to be released in time of energy needs, it has become clear it can actually function as a mediator of multiple metabolic and inflammatory signals $(12,13)$. Expanding adipose tissue contributes to increased circulating adipokines, including leptin, retinol binding protein 4 , resistin and visfatin (14), each of which has been shown to stimulate tumor growth. Adipokines released from adipose tissue contribute also to metabolic syndrome and T2DM leading to increased insulin and IGF-1, which in turn, promote tumor growth (14). The enzyme aromatase, responsible for converting androgens to estrogens, resides in adipose tissue and is increased in obesity, thereby increasing circulating estrogen levels (15). Expanding adipose tissue has been noted to harbor increased crownlike structures, composed of dying adipocytes surrounded by inflammatory cells, which are responsible for elevated levels of inflammatory cytokines, including IL-1, IL-6, IL-8, TNF $\alpha$, and others, all of which, can contribute to cancer pathogenesis. Adipose tissue inflammation promotes generation of reactive oxygen species, which may contribute to mutagenic changes. Obesity and obesogenic diets also foster changes in intestinal microbiota, which may contribute to tumor promoting metabolites. Moreover, recent studies have demonstrated that obesity induces epigenetic changes that may have long-lasting cancer promoting effects $(16,17)$.

The multiple pathways by which obesity promotes cancer, contributes to the great difficulty in disrupting the obesity-cancer linkage with a single or focused targeted approach (10). Accordingly, maintenance of normal weight or weight reduction in overweight/obese individuals is required to reduce the cancer promoting impact of obesity.

Lifestyle modification to affect intentional weight loss reduction in morbidly obese patients, has been shown to normalize circulating cancer risk factors including estrogens, insulins, IGF-1 and inflammatory cytokines 
$(18,19)$. Behavioral modification to decrease energy intake through diet control and increase energy expenditure through exercise seem to be simple solutions to the problem. Nonetheless, there have been limited controlled trials to demonstrate whether behavioral modification can reduce cancer risk. In fact, the continued increase in obese individuals on a worldwide basis demonstrate the refractoriness of this problem. Use of pharmacologic interventions have also not resulted in meaningful obesity control on an individual or population basis (20). In contrast, bariatric surgery has been shown to be the most effective approach to achieve significant and sustained weight loss $(21,22)$.

\section{Bariatric surgery criteria and approaches}

To qualify for bariatric surgery and receive healthcare coverage, patients are generally expected to meet the following criteria $(23,24)$ :
(I) $\mathrm{BMI} \geq 40 \mathrm{~kg} / \mathrm{m}^{2}$;

(II) $\mathrm{BMI} \geq 35 \mathrm{~kg} / \mathrm{m}^{2}$ or 100 pounds overweight, with at least one or more obesity-related comorbidities. These may include T2DM, hypertension, nonalcoholic fatty liver disease, cardiovascular diseases and/or others. However, patients with OACs as well as non-OACs are generally excluded;

(III) inability to achieve weight reduction, despite a medically supervised program of diet and exercise;

(IV) elimination of other treatable medical causes of obesity, such as adrenal, pituitary or thyroid disorders.

\section{Types of bariatric surgery}

There are currently many different types of weight loss surgical procedures available. In Table 1 and Figure 2 we provide an "at-a-glance" description of the most commonly performed surgeries, their advantages and complications.

Table 1 Current relevant bariatric surgical interventions

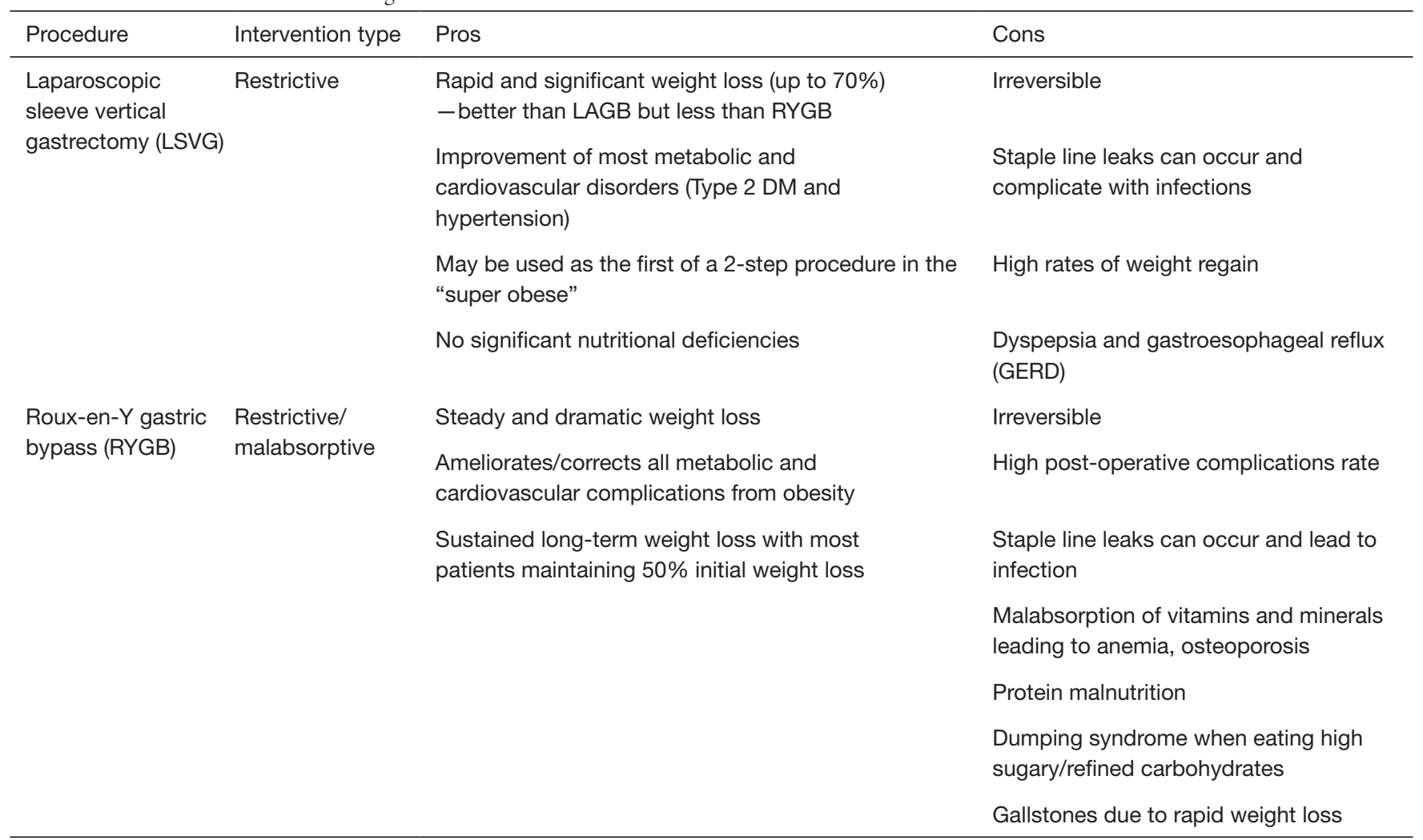

Table 1 (continued) 
Table 1 (continued)

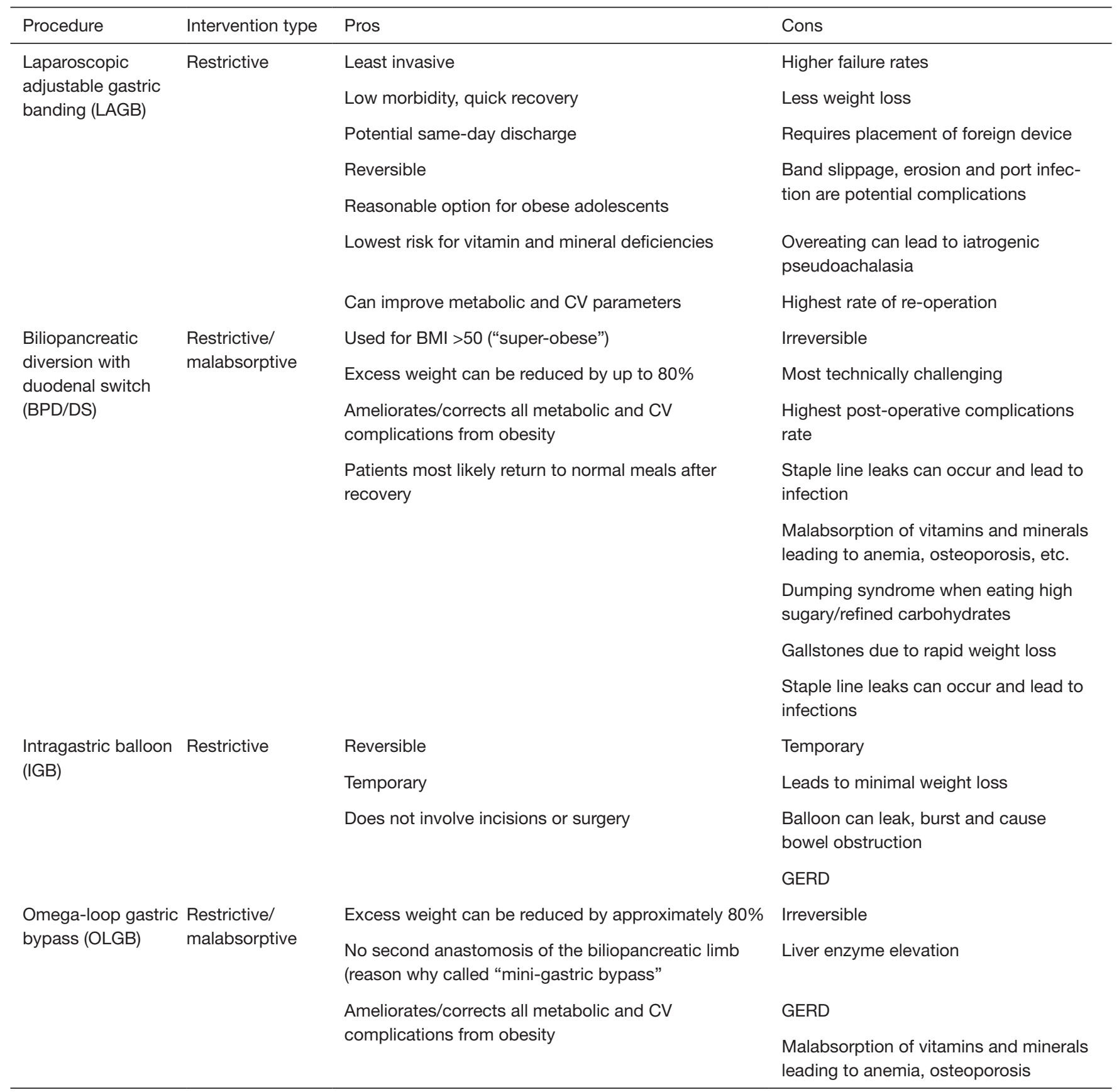

\section{Bariatric surgery for weight loss, metabolic \& cardiovascular disorders}

Bariatric surgery has now been demonstrated to be a highly successful and cost effective approach for control of morbid obesity and many of its consequences. It is however major surgery and requires a lifelong commitment to post-surgical management. Nonetheless, it is estimated that more than 228,000 bariatric surgical procedures are performed on an annual basis in the US and more than 580,000 in the world $(25,26)$.

In the Swedish Obese Subjects (SOS) Trial, a 
A

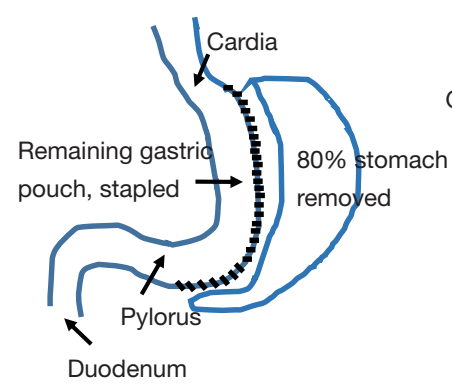

$E$

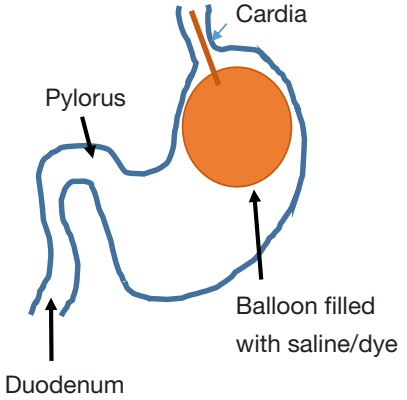

B

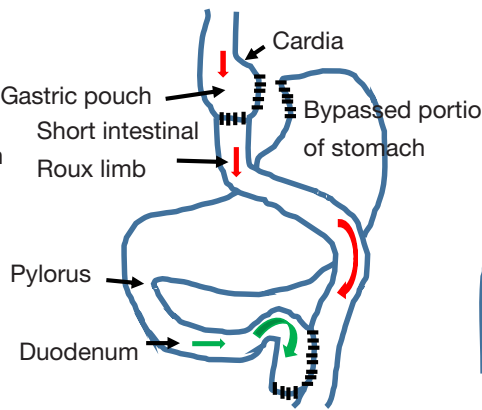

$\mathrm{F}$
C

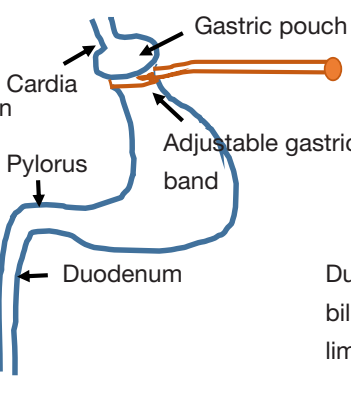

D

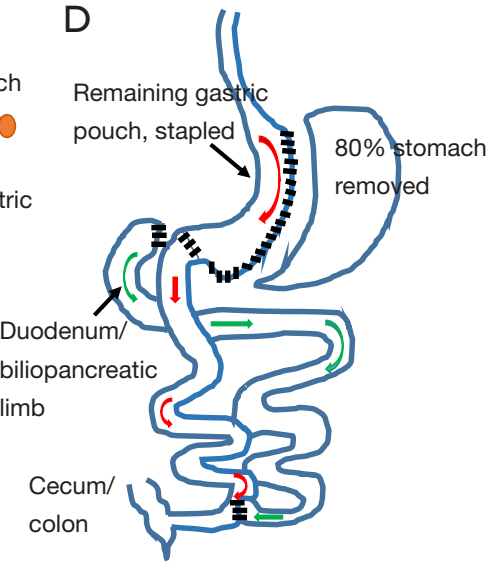

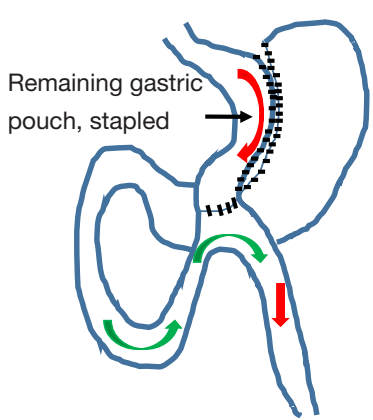

A = Laparoscopic Vertical Sleeve Gastrectomy

$B=$ Roux-en-Y Gastric Bypass

C = Laparoscopic Adjustable Gastric Banding

$\mathrm{D}=$ Biliopancreatic Diversion with Duodenal Switch

$\mathrm{E}=$ Intragastric balloon

$\mathrm{F}=$ Omega Loop Gastric Bypass

$\rightarrow$ Food flow

$\longrightarrow$ Bile and pancreatic juices flow

Figure 2 Commonly performed bariatric surgery procedures.

prospectively matched surgical intervention study, 2,010 obese patients (1,420 women, 590 men) who underwent bariatric surgery were compared prospectively to 2,037 controls (1,447 women, 590 men) who received conservative medical treatment $(21,27)$. Bariatric surgery consisted of either banding (adjustable or non-adjustable), vertical banded gastroplasty or gastric bypass. The surgical patients showed superior results for maximal weight loss achieved over first 2 years and sustained weight reduction maintained over 15-20 years. Both initial and sustained weight loss was greatest for gastric bypass. Patients undergoing bariatric surgery compared to non-surgical controls had higher remission rates for T2DM, were less likely to develop de novo T2DM, experienced fewer first time cardiovascular events and showed reduced cardiovascular deaths. As further discussed below, the incidence of first time cancers in the surgery group was lower than in the controls. Interestingly, the favorable effects of bariatric surgery on cardiovascular disease, cancer incidence and overall mortality could not be associated with weight loss $(21,27)$.

A recent report of the 5-year outcome results for the Surgical Treatment and Medications Potentially Eradicate Diabetes Efficiently (STAMPEDE) Trial, a prospective randomized control trial, compared medical therapy to bariatric surgery in 150 obese patients with T2DM. Bariatric surgery included either Roux-en- $Y$ gastric bypass or sleeve gastrectomy (22). During 5-year follow-up, bariatric surgery patients compared to medically managed controls showed greater weight loss, more normalization of glycated hemoglobin and superior outcomes relative to reduction of triglyceride levels, increased high density lipoprotein cholesterol levels and reduced use of insulin and other anti-diabetic agents. In addition, bariatric surgery patients showed reduced use of lipid lowering or antihypertensive agents. There were no cases of cancer reported in either study arm (22).

As described in the prospective studies outlined above and many others, bariatric surgery is clearly the most effective approach for obese individuals to achieve significant and sustained weight loss along with improvement of T2DM, metabolic syndrome, cardiovascular events, other obesityassociated comorbidities and overall survival $(21,22)$.

\section{Bariatric surgery for cancer prevention}

Although several trials, including the Swedish Obese Subjects Trial, discussed above, reported a decreased cancer incidence in bariatric surgery patients compared 
Table 2 Summary of studies assessing the impact of bariatric surgery in cancer risk

\begin{tabular}{|c|c|c|c|c|c|c|}
\hline Author & Study design & $\begin{array}{l}\text { Number of } \\
\text { subjects }\end{array}$ & $\begin{array}{l}\text { Overall, CA risk } \\
\text { or rate }\end{array}$ & OAC risk or rate & CA risk by gender & Procedures \\
\hline \multirow[t]{2}{*}{$\begin{array}{l}\text { Sjostrom et al. } \\
\text { (27); sos }\end{array}$} & \multirow{2}{*}{$\begin{array}{l}\text { Prospective } \\
\text { population-based } \\
\text { matched cohort }\end{array}$} & \multirow{2}{*}{$\begin{array}{l}S=2,010 \\
C=2,037 \\
W=2,867 \\
M=1,180\end{array}$} & \multirow[t]{2}{*}{$\begin{array}{l}H R=0.67 \\
(P=0.0009)\end{array}$} & $\begin{array}{l}\text { Melanoma, } H R=N D \\
(P=0.0055)\end{array}$ & $\begin{array}{l}\text { Women: } H R=0.58 \\
(P=0.0001)\end{array}$ & $\begin{array}{l}\text { LGB, HR }=0.54 \\
(P=0.026)-W \text { only }\end{array}$ \\
\hline & & & & $\begin{array}{l}\text { Hematologic, } H R=0.16 \\
(P=0.015)\end{array}$ & $\begin{array}{l}\text { Men: } H R=0.97 \\
(P=0.90)\end{array}$ & $\begin{array}{l}\text { VBG, } H R=0.60 \\
(P=0.0012)-W \text { only }\end{array}$ \\
\hline \multirow[t]{4}{*}{$\begin{array}{l}\text { Schauer et al. } \\
\text { (28); Kaiser } \\
\text { Permanente }\end{array}$} & \multirow[t]{4}{*}{$\begin{array}{l}\text { Retrospective, } \\
\text { matched cohort }\end{array}$} & \multirow{4}{*}{$\begin{array}{l}S=22,198 \\
C=66,427 \\
\text { over } 80 \% \\
\text { women }\end{array}$} & \multirow[t]{4}{*}{$\begin{array}{l}\mathrm{HR}=0.67 \\
(\mathrm{P}<0.001)\end{array}$} & $H R=0.59(P<.001)$ & $\begin{array}{l}\text { Women: } H R=0.64 \\
(P<0.001)\end{array}$ & $\begin{array}{l}\text { RYGB }(61 \%), \text { SG } \\
(27.2 \%), \text { LGB }(5.6 \%) \\
\text { all performed }\end{array}$ \\
\hline & & & & Colon, HR =0.59 (P=0.04) & $\begin{array}{l}\mathrm{OAC}, \mathrm{HR}=0.58 \\
(\mathrm{P}<0.001)\end{array}$ & $\begin{array}{l}\text { Outcomes per } \\
\text { procedure not } \\
\text { reported }\end{array}$ \\
\hline & & & & $\begin{array}{l}\text { Post-menopausal Breast, } \\
\mathrm{HR}=0.58(\mathrm{P}<0.001)\end{array}$ & \multicolumn{2}{|l|}{$\begin{array}{l}\text { Men: } H R=0.79 \\
(P=0.054)\end{array}$} \\
\hline & & & & $\begin{array}{l}\text { Pancreatic, } H R=0.46 \\
(P=0.04)\end{array}$ & \multicolumn{2}{|l|}{$\begin{array}{l}\mathrm{OAC}, \mathrm{HR}=0.70 \\
(\mathrm{P}=0.1)\end{array}$} \\
\hline \multirow{2}{*}{$\begin{array}{l}\text { Adams et al. } \\
\text { (29); Utah } \\
\text { Series }\end{array}$} & \multirow{2}{*}{$\begin{array}{l}\text { Retrospective, } \\
\text { population-based } \\
\text { matched cohort }\end{array}$} & \multirow{2}{*}{$\begin{array}{l}S=9,949 \\
C=9,628 ; \text { over } \\
80 \% \text { women }\end{array}$} & \multirow{2}{*}{$\begin{array}{l}\mathrm{HR}=0.76 \\
\mathrm{r}(\mathrm{P}=0.0006) \\
\text { overall } \mathrm{CA} \\
\text { mortality, HR } \\
=0.54(\mathrm{P}=0.001)\end{array}$} & \multirow{2}{*}{$\begin{array}{l}\mathrm{HR}=0.62(\mathrm{P}<0.0001) \\
\text { Endometrial, } \mathrm{HR}=0.22 \\
(\mathrm{P}<0.0001) ; \mathrm{OAC} \text { mortality, } \\
\mathrm{HR}=0.54(\mathrm{P}=0.02)\end{array}$} & $\begin{array}{l}\text { Women: } \mathrm{HR}=0.73 \\
(\mathrm{P}=0.0004)\end{array}$ & \multirow[t]{2}{*}{ Only RYGB } \\
\hline & & & & & $\begin{array}{l}\text { Men: HR =1.02 } \\
(0.91)\end{array}$ & \\
\hline $\begin{array}{l}\text { Ward et al. (34); } \\
\text { US - University } \\
\text { Health System } \\
\text { Consortium }\end{array}$ & $\begin{array}{l}\text { Retrospective } \\
\text { cohort }\end{array}$ & $\begin{array}{l}44,345 \\
\text { cases of } \\
\text { Endometrial } \\
\text { CA }\end{array}$ & N/A & Endometrial, RR $=0.19$ & $\mathrm{~N} / \mathrm{A}$ & $\begin{array}{l}\text { Outcomes per } \\
\text { procedure not } \\
\text { reported }\end{array}$ \\
\hline Tee et al. (35) & $\begin{array}{l}\text { Meta-analysis } \\
6 \text { studies } \\
\text { ( } 2 \text { prospective and } \\
4 \text { retrospective) }\end{array}$ & $\begin{array}{l}S=21,058 \\
C=30,682\end{array}$ & $\begin{array}{l}R R=0.55 \\
(P<0.0001)\end{array}$ & $\begin{array}{l}\text { No statistically significant } \\
\text { effect on different CA types } \\
\text { (breast, melanoma, CRC, } \\
\text { NHL, pancreatic) }\end{array}$ & $\begin{array}{l}\text { Women: } R R=0.68 \\
(P<0.0001) \\
\text { Men: } R R=0.99 \\
(P=0.937)\end{array}$ & Not reported \\
\hline
\end{tabular}

Table 2 (continued) 
Table 2 (continued)

\begin{tabular}{|c|c|c|c|c|c|c|}
\hline Author & Study design & $\begin{array}{l}\text { Number of } \\
\text { subjects }\end{array}$ & $\begin{array}{l}\text { Overall, CA risk } \\
\text { or rate }\end{array}$ & OAC risk or rate & CA risk by gender & Procedures \\
\hline \multirow{3}{*}{$\begin{array}{l}\text { Ostlund et al. } \\
\text { (31); Swedish } \\
\text { National Patient } \\
\text { Register }\end{array}$} & \multirow{3}{*}{$\begin{array}{l}\text { Retrospective, } \\
\text { population-based } \\
\text { observational } \\
\text { cohort }\end{array}$} & \multirow[t]{3}{*}{$\begin{array}{l}S=13,123 \\
77 \% \text { women }\end{array}$} & \multirow[t]{3}{*}{$\begin{array}{l}\mathrm{SIR}=1.04 \\
(0.93-1.17)\end{array}$} & $\begin{array}{l}\text { Breast, SIR =0.55 }(0.44- \\
0.68)\end{array}$ & $\begin{array}{l}\text { Women: } \mathrm{SIR}=0.97 \\
(0.85-1.11)\end{array}$ & $\begin{array}{l}\mathrm{GB}, \mathrm{SIR}=1.05 \\
(0.87-1.27)\end{array}$ \\
\hline & & & & $\begin{array}{l}\text { Endometrial, SIR =2.15 } \\
(1.62-2.81)\end{array}$ & \multirow[t]{2}{*}{$\begin{array}{l}\text { Men: } \operatorname{SIR}=1.41 \\
(1.09-1.81)\end{array}$} & $\begin{array}{l}\text { VBG, SIR }=1.05 \\
(0.89-1.24)\end{array}$ \\
\hline & & & & $\mathrm{CRC}, \mathrm{SIR}=2.14(1.33-3.22)$ & & \\
\hline \multirow[t]{4}{*}{$\begin{array}{l}\text { Aravani et al. } \\
\text { (32); English } \\
\text { National Health } \\
\text { Service }\end{array}$} & \multirow[t]{4}{*}{$\begin{array}{l}\text { Retrospective, } \\
\text { population-based } \\
\text { observational } \\
\text { cohort }\end{array}$} & \multirow[t]{4}{*}{$\begin{array}{l}S=39,747 \\
C=962,860 ; \\
76.6 \% \text { women } \\
\text { in S; } 62.9 \% \text { in } \\
\text { C }\end{array}$} & \multirow[t]{4}{*}{ Not reported } & $\begin{array}{l}\text { CRC, SIR }=1.26(0.92-1.71) \\
\text { for } S \text { and } S I R=1.12(1.08- \\
1.16) \text { for } C\end{array}$ & $\begin{array}{l}\text { Women: CRC, SIR } \\
=1.19(0.79-1.74) \\
\text { for } \mathrm{S} \text { and } \mathrm{SIR}=1.02 \\
(0.97-1.08) \text { for } \mathrm{C}\end{array}$ & $\begin{array}{l}\text { Restrictive surgery, } \\
\text { SIR }=1.41 \\
(0.94-2.02)\end{array}$ \\
\hline & & & & $\begin{array}{l}\text { Breast, SIR =0.76 }(0.62- \\
0.92)\end{array}$ & \multirow{3}{*}{$\begin{array}{l}\text { Men: CRC, SIR } \\
=1.41(0.81-2.29) \\
\text { for } S \text { and } \text { SIR }=1.21 \\
(1.15-1.26) \text { for } C\end{array}$} & \multirow{3}{*}{$\begin{array}{l}\text { Restrictive and } \\
\text { malabsorptive } \\
\text { I surgery, SIR =1.05 } \\
(0.57-1.76)\end{array}$} \\
\hline & & & & $\begin{array}{l}\text { Endometrial, SIR }=2.98 \\
(2.25-3.90) \text { for } \mathrm{S} \text { and } \mathrm{SIR}= \\
2.60(2.48-2.73) \text { for } \mathrm{C}\end{array}$ & & \\
\hline & & & & $\begin{array}{l}\text { Kidney, SIR =3.06 }(2.08- \\
4.34) \text { for } S \text { and } S I R=1.78 \\
(1.68-1.89) \text { for } C\end{array}$ & & \\
\hline \multirow{2}{*}{$\begin{array}{l}\text { Mackenzie et al. } \\
\text { (36); Hospital } \\
\text { Episode } \\
\text { Statistics } \\
\text { Database in } \\
\text { England }\end{array}$} & \multirow{2}{*}{$\begin{array}{l}\text { Retrospective, } \\
\text { population-based } \\
\text { matched cohort }\end{array}$} & \multirow{2}{*}{$\begin{array}{l}S=8,794 \\
C=8,794 \\
80.3 \% \\
\text { women }\end{array}$} & \multirow{2}{*}{ Not reported } & $\begin{array}{l}\text { Prostate, OR =0.33 }(0.17- \\
0.76)\end{array}$ & \multirow{2}{*}{$\begin{array}{l}\text { Men: CRC, OR } \\
=1.50(0.53-4.23)\end{array}$} & $\begin{array}{l}\text { LGB: OR }=0.34 \\
(0.23-0.48) \text {, overall } \\
\text { hormone-related CA }\end{array}$ \\
\hline & & & & $\begin{array}{l}\text { CRC, OR =2.19 } \\
(1.21-3.96)\end{array}$ & & $\begin{array}{l}\text { SG: OR }=0.21 \\
(0.07-0.61)\end{array}$ \\
\hline
\end{tabular}

SOS, Swedish Obese Study; S, study subjects; C, controls; W, women; M, men; LGB, laparoscopic gastric banding; GB, gastric banding; VBG, vertical banded gastrectomy; RYGB, Roux-en-Y gastric bypass; SG, sleeve gastrectomy; ND, not determined; CRC, colorectal cancer; RR, risk reduction; N/A, not applicable; CRC, colorectal cancer; NHL, non-Hodgkin's lymphoma; SIR, standardized incidence ratio. 
to controls, other studies have reported the opposite (21,28-32) (Table 2). This controversy is due, in part, to the difficulty in performing long-term prospective controlled cancer prevention studies as compared to their more successful use for evaluation of weight loss, metabolic and cardiovascular benefits of bariatric surgery. In the SOS Trial, patients were 37-60 years old with a $B M I \geq 34 \mathrm{~kg} / \mathrm{m}^{2}$ for men and $\geq 38 \mathrm{~kg} / \mathrm{m}^{2}$ for women, at time of study entrance and were followed for 10.9 years $(0-18.1)$ years. Women who underwent surgery showed a reduced incidence of new cancers compared to controls with significant differences for malignant melanoma and hematologic malignancies. Overall, bariatric surgery reduced cancer risk by $42 \%$ (HR $0.58,0.44-0.77$ ) in women, while in men there was no cancer risk reduction observed (HR 0.97, 0.62-1.52). In men, none of the procedures decreased cancer incidence, whereas in women, the benefits of banding and vertical banded gastroplasty were similar. In women, undergoing surgery was a significant predictor of lower cancer incidence, HR 0.38 (0.20-0.73), while change in body weight was not $(21,27)$.

In a retrospective matched cohort observational study conducted among participants in the Kaiser Permanente Health Insurance and Care Delivery System, 22,198 subjects who underwent bariatric surgery and 66,427 matched non-surgical subjects, age 18-79, mean age $45 \pm 11$ years were followed up to 10 years, mean 3.5 years. Women who underwent bariatric surgery compared to controls had a significant reduction in cancer incidence HR 0.64 (0.57-0.72), whereas there were no statistically significant reductions in cancer risk among men. The reduction in cancer incidence for women was noted for OAC's at HR 0.58 (0.49-0.67) compared to non-OAC's HR 0.74 (0.62-0.89). OAC's that showed significant reduction in bariatric surgery treated women, included post-menopausal breast, colon, endometrial and pancreatic. While the rates of liver, gallbladder, multiple myeloma, ovarian, rectal and thyroid cancers were also decreased, these effects did not reach statistical significance. In this study, cancer risk reduction was correlated with weight loss after 1 year with $14 \%$ reduction in cancer risk associated with each $10 \%$ reduction in weight $(28,37)$.

In another retrospective cohort registry study, a single group of bariatric surgeons in Utah compared 6,596 Rouxen-Y bariatric surgery patients with 9,442 controls. The surgical group consisted of $86 \%$ women, $14 \%$ men. They were matched for BMI at time of surgery with state of Utah driver's license applicants. Over a 24-year period (mean 12.5 years), bariatric surgery patients compared to controls showed reduction in total cancer incidence HR 0.76 (0.65-0.89) and in OAC incidence HR 0.62 (0.49-0.78), but not in non-OACs HR $0.91(0.73-1.12)$. Risk reduction was restricted to women HR 0.73 (0.62-0.87), with HR 1.02 $(0.69-1.12)$ observed in men. In this study the differential effects on OACs however, is somewhat distorted since assignment to OAC $v s$. non-OAC's does not comport with recent designations (1). For example, Non-Hodgkin lymphoma and leukemia are included as OAC's whereas thyroid is not. Notably however, uterine cancer, which is an $\mathrm{OAC}$, achieved the greatest significance for differences between surgical vs. controls $(0.17 / 1,000$ vs. $0.88 / 1,000$ person-years; $\mathrm{P}<0.0001)$. Total cancer death rate in the bariatric surgery group was $41 / 6,596$ patients or HR 0.50 per 1,000 person-years compared to $107 / 9,492$ or 0.94 per 1,000 person-years leading to HR $0.54(0.37-0.78), \mathrm{P}=0.01$ for surgery compared to controls. Interestingly, the death rate for surgical patients who developed cancer was $16.14 \%$ compared to $22.4 \%$ for controls who developed cancer $(29,30,38)$.

In a Canadian observational two cohort study at McGill University, comparing 1,035 morbidly obese patients who underwent bariatric surgery to 5,746 patients matched for age, sex, morbid obesity, over a 5-year follow-up period, there was $2 \%$ cancer development in the surgical group $v$ s. $8.45 \%$ in controls for relative risk, RR, of 0.2 . The most common procedure was Roux-en-Y gastric bypass (73.4\%), followed by vertical banded gastroplasty (18.7\%). However, no results comparing surgical procedures on weight loss were reported relative to the procedures. Although the surgery and control groups were $34.1 \%$ and $36 \%$ male respectively, there was no difference of cancer incidence by sex. Moreover, no outcomes were noted according to ethnic background. While all cancer types were reduced in the survival groups, most significantly reduced was breast, which occurred at $1.16 \%$ in surgery group compared to $6.31 \%$ in controls, relative risk (RR) 0.17 (0.098-0.311) (33).

Focusing on uterine malignancy, a retrospective study of women registered in the US University Health System Consortium with data contributed by 116 US academic medical centers and 278 affiliated hospitals, 44,345 diagnosis of uterine malignancy were identified of which 408/100,000 occurred among women who had previously undergone bariatric surgery for obesity, whereas 1,409 cases/100,000 occurred among obese women who had not undergone bariatric surgery. For obese women who had undergone bariatric surgery compared to non-surgical 
controls, the RR for uterine malignancy was 0.19 . The $\mathrm{RR}$ was further reduced to 0.17 for these women who had undergone bariatric surgery and maintained normal weight (34). In this study the authors did not discriminate between types of bariatric procedures.

In a meta-analysis of six bariatric surgery studies ( 2 prospective and 4 retrospective) with intervention and comparison control groups, using both restrictive and malabsorptive techniques, 51,740 obese patients were followed for cancer incidence, risk or cancer related mortality for mean of 5 to 16 years. Comparison of cancer incidence, diagnosis or mortality among 21,058 surgery patients compared to 30,682 controls demonstrated overall benefit for surgery. Overall, cancer RR for the bariatric surgery group was $0.55(0.41-0.73)$. Bariatric surgery was protective for women, RR 0.68 (0.60-0.77), but not men RR 0.99 (0.74-1.32). There were no statistically significant risk reductions for any specific cancer subtype (35).

In contrast to the primary studies and meta-analysis reported above, a Swedish nationwide retrospective population register-based study spanning 1980-2006 found no overall decrease in the standardized incidence ratios (SIRs) of cancer associated with bariatric surgery over time (31). However, the authors suggested that there was an increase in colorectal cancer (CRC) SIRs following bariatric surgery. In subsequent follow-up (39) using extended data, 19802009, the same group identified 70 CRC among 15,095 bariatric surgery patients (approximately $2 / 3$ female) and 373 CRC among 62,016 obese controls. These results are reported as showing a cumulative CRC incidence in the bariatric surgery group of 48/100,000 person-years compared to $91 / 100,000$ person-years in the obese nonsurgery group. Adjusting this incidence data to SIRs in which observed numbers are expressed relative to expected numbers for that group, the authors derived a total CRC SIR of 1.6 for bariatric surgery cohort, compared to 1.26 for non-surgical cohort. Based on these adjusted calculations, they suggest that those undergoing bariatric surgery had a higher SIR for CRC post intervention. The increased risk for CRC in obesity surgery patients occurred in both men and women and reached statistical significance in the two most commonly performed procedures in the surgical cohort (vertical banded gastrectomy and adjustable gastric banding).

To determine impact of prior bariatric surgery on outcome of patients who develop cancer, the Swedish Patient Registry study, followed from 1980-2012, was further analyzed to show that obesity surgery patients who subsequently developed CRC had reduced disease specific survival compared to non-surgical obesity patients. The bariatric cohort had undergone similar rates of RYGB (26\%), gastric banding (33\%) and vertical banded gastroplasty (36\%). A minority of patients (5\%) underwent a malabsorptive procedure otherwise not specified. The decreased survival in CRC patients was reported as being primarily due to greater than three-fold increase in risk associated with rectal cancer patients (40). Though numbers were small, there was a borderline correlation between CRC-specific mortality and restrictive procedures, which accounted for the majority of interventions in this cohort.

In a subsequent national population-based retrospective observation study, some of the same investigators queried patients seen at English NHS hospitals using the English Hospital Episode Statistics dataset covering the period 1997-2012, to identify 43 diagnosis of CRC among 39,747 bariatric surgery patients $(76.6 \%$ female) compared to diagnosis of 3,237 cases CRC among 962,860 (62.9\% female) obese non-surgical patients. Notably these two groups were not compared directly, but each was compared to the English background population. Cumulative incidence CRC in the bariatric surgery group was 30/100,000 patientyears, while in the obesity control group, it was $91 / 100,000$ patient-years. And while overall SIR for CRC was not significantly increased in the surgical group, a higher risk for CRC was reported for bariatric surgery patients age 50 or older (SIR: 1.47; 95\% CI, 1.02-2.06), with no differences noted between surgical procedure types. The non-surgical group has a slightly increased risk for CRC when compared to the background population (SIR: $1.21 ; 95 \%$ CI, 1.15-1.26), and was increased in males (32).

In yet another analysis of an English populationbased patient cohort using the Hospital Episode Statistics database, 8,794 bariatric surgery patients were compared to the same number propensity matched controls with median follow-up of 55.5 months. In this study, time was measured from first diagnosis of obesity rather than from time of surgery. The same author group reported that compared to non-surgical control, obese patients that underwent bariatric surgery showed decreased risk for breast cancer odds ratio (OR) 0.25 (0.19-0.33), endometrial cancer OR $0.21(0.13-0.35)$ and prostate cancer OR $0.37(0.17-0.76)$ with gastric bypass constituting the most effective approach to reducing incidence of these hormone related cancers (OR 0.16). Gastric banding and sleeve gastrectomy were also protective (OR 0.34 and 0.21 , respectively). In contrast, bariatric surgery was associated with an increased 
risk of CRC in both men and women who underwent gastric bypass (OR 2.63) but not gastric banding. In these studies, the occurrence of CRC in obesity surgery patients continued to increase with progressive time following surgery (36).

\section{Bariatric surgery and CRC risk}

In each of these last eight reports, two from Sweden, three from the US, two from England, and one from Canada, the absolute CRC incidence in the obesity surgery group was less than in the obesity non-surgical group. However, in those studies where data was adjusted to reflect SIRs, and/or use of propensity-matched controls, there was a suggestion of greater risk for CRC in the bariatric surgery group. Although the latter approach was designed to provide a more relevant reference population, questions remain regarding appropriateness of factors included and/or omitted in identifying these comparisons.

These reports suggesting that obesity surgery may result in increased risk of CRC are complicated and controversial. The confusion stems, in part from the difficulty in conducting real time randomized controls with comparable follow-up and the resultant use of heavily and variably derived comparative groups and statistical manipulation. Thus, controls are usually not standardized for weight changes, dietary differences, physical activity or medications, such as aspirin, insulin and hormones, all of which can profoundly impact CRC incidence.

It is noteworthy that bariatric surgery patients, undergoing successful weight loss and metabolic change, require decreased lipid lowering agents (22). Thus, reductions in statin usage, which has been shown to have a cancer preventive effect, could remove a potentially protective intervention $(41,42)$. These issues have previously been extensively discussed but not resolved (43-47).

Moreover, another area of increasing interest is the gut microbiome's role not only in the pathogenesis of obesity (48) and its metabolic complications but also in that of malignancies and their response to treatments $(49,50)$. We now understand that obesity correlates with poor diversity of the gut microbiome, and that more homogeneous gut floras have a "pro-inflammatory" phenotype (51) compared to the healthier and diverse gut signatures. Several studies in both animals and humans have demonstrated changes in the composition of the gut microbiome after bariatric surgery, particularly the ones that alter the luminal tract extent and its connections with the biliopancreatic system (such as
RYGB) (52,53). Fecal profiles post-RYGB in animal studies disclose an expected decrease in bile acid composition and a shift from protein degradation to protein putrefaction phenotype (52). To what extent such changes could promote colonic malignancies is unclear.

A very interesting hypothesis generating prospective study has looked into colonic epithelial cell proliferation of 24 subjects undergoing RYGB surgery. Biopsies were obtained on the day of surgery and 6 months after. Serum and colonic mucosa levels of pro-inflammatory cytokines such as IL-6 and TNF-alpha were reduced after RYGB procedure. However, the investigators noted a significant increase in the mitotic activity of colonic cells following surgery as well as increased expression of the pro-inflammatory and tumorigenic COX-1 and COX-2 molecules (54).

It is also important to shed light into the fact that patients who undergo bariatric surgery are encouraged to promote radical dietary changes not only to continue to achieve success from the intervention but also to be able to keep an adequate caloric intake. The intake of dietary fiber not only has been associated with decreased risk of CRC (55) but also with better prognosis after a diagnosis of non-metastatic CRC (56). Following bariatric surgery, the intake of raw vegetables and fruits, for instance, may be limited and to what extent this lower fiber intake could lead to increased CRC risk is unknown. Clearly, more research is needed, both at the mechanistic level and preventive controlled clinical trials with long-term follow-up.

\section{Bariatric surgery to prevent cancer progression, recurrence and mortality}

The impact of obesity on cancer progression, recurrence and mortality can be considered to be mediated by both direct and indirect pathways. The direct pathway is attributed to adipose tissue derived adipokines and cytokines which directly promote tumor growth and metabolites $(10,11)$. The indirect pathway may be mediated by metabolic consequences of obesity, such as T2DM with accompanying high levels of tumor promoters such as insulin and IGF-1. The use of bariatric surgery for primary prevention of cancer is predicated on disrupting both of these pathways as well as preventing other possible mechanisms including epigenetic effects and changes in microbiota. There is clear evidence that obesity and abnormal glucose metabolism is associated with worse prognosis in patients with established cancer (13). Bariatric surgery has already been shown to 
successfully achieve weight loss among cancer survivors (57) but long-term effects have not been reported. In addition to weight loss, the rapid metabolic changes following bariatric surgery, especially decreased T2DM and lowered insulin levels could provide rapid reduction in major cancer promoting factors. In consideration of these potential benefits, bariatric surgery in obese patients following a diagnosis and/or accompanying cancer treatment has previously been considered (58). However, since bariatric surgery is generally contraindicated in patients with recent onset cancer, this approach has not been systematically evaluated. Randomized control trials to determine beneficial effects of bariatric surgery in obese women with breast or endometrial cancer, as an adjunct to primary therapy seems to be a reasonable approach for multiple reasons:

(I) sustained weight loss using behavioral modifications in obese patients with breast or uterine cancer has been difficult to achieve;

(II) bariatric surgery has been shown to successfully achieve weight control in obese patients after diagnosis of cancer (59);

(III) bariatric surgery for cancer prevention is more effective in women compared to men and is particularly effective in breast and endometrial cancers;

(IV) women with breast cancer in its early stages do not have metastatic abdominal disease;

(V) studies in endometrial cancer are warranted since it is the tumor in women with worse prognostic effects due to obesity (60).

\section{Factors affecting bariatric cancer prevention}

\section{Ethnicity}

The prevalence of obesity and associated comorbidities in the African American population is reported to be greater than any other racial, ethnic group (61). However, it is difficult to assess the impact of ethnic differences on use of bariatric surgery to prevent cancer since the demographics are rarely provided in the bariatric surgery literature, and even when they are, their relation to outcomes are usually not discussed. This lack of information is probably multifactorial including differences in frequency that bariatric surgery is recommended, cultural lack of stigma and acceptability of large body size, concern about consequences and perception that bariatric surgery is the last resort (62-64). In a limited retrospective study comparing 9 African Americans to 41 Whites, 1 year after gastric bypass surgery, the African Americans showed 26\% weight loss, while Whites lost 38\% (65). Feasibility and success of bariatric surgery in African American patients has more recently been demonstrated with report of a retrospective review of 87 black patients with super morbid obesity, $\mathrm{BMI}=56.7 \pm 6.4 \mathrm{~kg} / \mathrm{m}^{2}$ who after 1 year follow-up had achieved BMI $40.1 \pm 7.7 \mathrm{~kg} / \mathrm{m}^{2}$. These patients showed significant improvement in hypertension, T2DM and hyperlipidemia. Changes in cancer occurrence or deaths were not reported (66).

\section{Sex}

Several large studies have now shown that bariatric surgery reduces cancer incidence in women but not men. The mechanism(s) of this difference has not been explained. Nonetheless, the predominant reduction in cancer incidence in women occurs with hormone dependent cancers, including post-menopausal breast and endometrial, but also, with melanoma, and hematological malignancies. While some series indicate that men derive no cancer preventive benefit from bariatric surgery, others indicate significant decreased incidence in prostate cancer (36). Differences in these studies may be associated with relatively lower numbers of men in most bariatric surgery trials. In addition, since prostate cancer is commonly diagnosed in older men, these studies may require longer follow-up before prostate cancer differences become apparent. Finally, it should be noted that the relation of prostate cancer with obesity is associated with high-risk disease, which is more common in African American men than Caucasians (2). However, most bariatric surgery trials report limited numbers of African Americans.

\section{Weight loss}

It is interesting that some studies report that the cancer preventive effect of bariatric surgery is not associated with weight loss $(21,27)$ whereas others report a clear association with each $10 \%$ loss in weight resulting in $14 \%$ reduction in cancer risk $(28,37)$. The controversy over whether cancer prevention is associated with weight loss is important but unresolved.

\section{Procedure types}

A protective effect of bariatric surgery has been attributed to both restrictive and combined restrictive/malabsorptive 
procedures in the few studies that compared the impact of individual interventions in OAC risk reduction $(27,36,38)$. The majority of studies that have looked at the impact of bariatric surgery in CA risk reduction, however, are either not able to provide specifics on the types of procedure performed or do not specify associations based on procedure types.

Most studies that have associated bariatric surgery to an increased CRC risk have also not discriminated between different operations and deleterious effects $(32,40)$. The group that demonstrated increased SIR for CRC in the retrospective Swedish registry, saw a negative impact for the 2 most commonly performed procedures in the surgical cohort: vertical banded gastroplasty and adjustable gastric banding (39), but not with RYGB. Another study looking at an English cohort described an association only with RYGB but not with the purely restrictive gastric banding surgery (36). Therefore, it seems there is insufficient data to recommend one procedure versus another in terms of its protective OAC effects.

\section{Mechanisms}

Despite clearly demonstrated multiple pathways by which obesity impacts cancer $(10,11)$, studies focused on mechanism(s) by which bariatric surgery affects cancer incidence are limited. However, some have examined effects of bariatric surgery on potential biomarkers and mediators of the obesity-cancer linkage.

In one study of 72 women with obesity $>40 \mathrm{~kg} / \mathrm{m}^{2}$, gastric bypass or sleeve gastrectomy resulted in weight loss and reduction of endometrial proliferation markers (Ki67, oncogene signaling pAKT, with restriction of glandular PTEN expression) (67). The series was also remarkable for detection of endometrial carcinoma or atypical hyperplasia (AH) in 10 women (14\%) at baseline endometrial biopsy. Interestingly, in most cases (5/6) AH resolved after bariatric surgery or intrauterine progesterone.

The possibility that CRC is the only malignancy reported to increase after bariatric surgery has been attributed to unique changes in the terminal GI tract after bariatric surgery, including rectal mucosal hyper-proliferation, increased expression of macrophage migration inhibitory factor and change in intestinal microbiota $(39,44,68)$, as we previously discussed.

\section{Conclusions}

In summary, bariatric surgery is most useful for weight control and especially T2DM, as well as, cardiovascular consequences of obesity. Other comorbidities that have been shown to respond to bariatric surgery include metabolic syndrome, dyslipidemia, hypertension and others. While controversy exists regarding the incidence of cancer following bariatric surgery, most trials indicate that bariatric surgery reduces overall risk of cancer development. This risk reduction is predominantly in women compared to men and most significantly for breast and endometrial cancers.

While a high percentage of obese patients undergoing bariatric surgery show early and sustained weight reduction and T2DM control $(21,22)$, the preventive effects of bariatric surgery on cancer incidence has been estimated to require 71 gastric bypass procedures to prevent one incident case of cancer. Given this level of effect and since bariatric procedures are major surgery that require intense followup, it is difficult to recommend bariatric surgery as a cancer preventive approach in obese patients. However, when bariatric surgery is recommended for control of obesity and other comorbidities, its cancer preventive effects should be noted as an added benefit. Evidence that bariatric surgery increases risk for CRC has not been substantiated in multiple studies and should not be considered a contraindication to surgery when recommended for weight loss or control of metabolic diseases. Nonetheless, the controversy requires continued follow-up and further research on potential mechanisms.

With growing evidence that obesity promotion of cancer may be epigenetically determined $(16,17)$, with long latent periods, it is possible that bariatric surgery during middle age years may already be too late to prevent cancer. Accordingly, it is possible that preventive strategies for cancer, as well as prevention of metabolic and cardiovascular comorbidities of obesity will need to be considered at younger ages.

It is important to note that patients undergoing bariatric surgery for weight loss, should not expect to have their cancer risk eliminated or reduced beyond that of the non-obese, normal weight population. Rather, if successful, it is expected that bariatric surgery may reduce the risk of OAC to that of a healthy normal weight person. Accordingly, individuals who undergo bariatric surgery should at least, follow all standard age-appropriate cancer prevention recommendations and screening guidelines, especially those for CRC.

\section{Acknowledgments}

Funding: NA Berger was supported in part, by NIH grants 
GI SPORE P50 CA150964, BETRNet U54 CA163060, and RO1 MD009699.

\section{Footnote}

Provenance and Peer Review: This article was commissioned by the Guest Editor (Muhammed Ashraf Memon) for the focused issue "Bariatric Surgery" published in Annals of Translational Medicine. The article was sent for external peer review organized by the Guest Editor and the editorial office.

Conflicts of Interest: The focused issue "Bariatric Surgery" was commissioned by the editorial office without any funding or sponsorship. The authors have no conflicts of interest to declare.

Ethical Statement: The authors are accountable for all aspects of the work in ensuring that questions related to the accuracy or integrity of any part of the work are appropriately investigated and resolved.

Open Access Statement: This is an Open Access article distributed in accordance with the Creative Commons Attribution-NonCommercial-NoDerivs 4.0 International License (CC BY-NC-ND 4.0), which permits the noncommercial replication and distribution of the article with the strict proviso that no changes or edits are made and the original work is properly cited (including links to both the formal publication through the relevant DOI and the license). See: https://creativecommons.org/licenses/by-nc-nd/4.0/.

\section{References}

1. Lauby-Secretan B, Scoccianti C, Loomis D, et al. Body Fatness and Cancer--Viewpoint of the IARC Working Group. N Engl J Med 2016;375:794-8.

2. Barrington WE, Schenk JM, Etzioni R, et al. Difference in Association of Obesity With Prostate Cancer Risk Between US African American and Non-Hispanic White Men in the Selenium and Vitamin E Cancer Prevention Trial (SELECT). JAMA Oncol 2015;1:342-9.

3. De Pergola G, Silvestris F. Obesity as a major risk factor for cancer. J Obes 2013;2013:291546.

4. Collaboration NCDRF. Trends in adult body-mass index in 200 countries from 1975 to 2014: a pooled analysis of 1698 population-based measurement studies with 19.2 million participants. Lancet 2016;387:1377-96.
5. Collaborators GBDO, Afshin A, Forouzanfar MH, et al. Health Effects of Overweight and Obesity in 195 Countries over 25 Years. N Engl J Med 2017;377:13-27.

6. Lopez-Suarez A. Burden of cancer attributable to obesity, type 2 diabetes and associated risk factors. Metabolism 2019;92:136-46.

7. O'Connell JB, Maggard MA, Liu JH, et al. Rates of colon and rectal cancers are increasing in young adults. Am Surg 2003;69:866-72.

8. Berger NA. Young Adult Cancer: Influence of the Obesity Pandemic. Obesity (Silver Spring) 2018;26:641-50.

9. Sung H, Siegel RL, Rosenberg PS, et al. Emerging cancer trends among young adults in the USA: analysis of a population-based cancer registry. Lancet Public Health 2019;4:e137-47.

10. Hursting SD, Digiovanni J, Dannenberg AJ, et al. Obesity, energy balance, and cancer: new opportunities for prevention. Cancer Prev Res (Phila) 2012;5:1260-72.

11. Berger NA. Obesity and cancer pathogenesis. Ann N Y Acad Sci 2014;1311:57-76.

12. Hotamisligil GS. Inflammation and metabolic disorders. Nature 2006;444:860-7.

13. Meyerhardt JA, Sato K, Niedzwiecki D, et al. Dietary glycemic load and cancer recurrence and survival in patients with stage III colon cancer: findings from CALGB 89803. J Natl Cancer Inst 2012;104:1702-11.

14. Saygin C, Reizes O, Berger NA. Adipocytes, Adipocytokines, and Cancer. In: Reizes O, Berger NA, editor. Adipocytokines, Energy Balance, and Cancer. Berlin: Springer, 2012:1-19.

15. Kirschner MA, Schneider G, Ertel NH, et al. Obesity, androgens, estrogens, and cancer risk. Cancer Res 1982;42:3281s-5s.

16. Li R, Grimm SA, Chrysovergis K, et al. Obesity, rather than diet, drives epigenomic alterations in colonic epithelium resembling cancer progression. Cell Metab 2014;19:702-11.

17. Berger NA, Scacheri PC. Targeting Epigenetics to Prevent Obesity Promoted Cancers. Cancer Prev Res (Phila) 2018;11:125-8.

18. Linkov F, Maxwell GL, Felix AS, et al. Longitudinal evaluation of cancer-associated biomarkers before and after weight loss in RENEW study participants: implications for cancer risk reduction. Gynecol Oncol 2012;125:114-9.

19. Byers T, Sedjo RL. Does intentional weight loss reduce cancer risk? Diabetes Obes Metab 2011;13:1063-72.

20. Saunders KH, Kumar RB, Igel LI, et al. Pharmacologic Approaches to Weight Management: Recent Gains and 
Shortfalls in Combating Obesity. Curr Atheroscler Rep 2016;18:36.

21. Sjostrom L. Review of the key results from the Swedish Obese Subjects (SOS) trial - a prospective controlled intervention study of bariatric surgery. J Intern Med 2013;273:219-34.

22. Schauer PR, Bhatt DL, Kirwan JP, et al. Bariatric Surgery versus Intensive Medical Therapy for Diabetes - 5-Year Outcomes. N Engl J Med 2017;376:641-51.

23. Dimick JB, Birkmeyer NJ. Rethinking eligibility criteria for bariatric surgery. JAMA 2014;312:953-4. PubMed http://dx.doi.org/10.1001/jama.2014.3836</jrn>

24. Stahl JM, Malhotra S. Obesity Surgery Indications And Contraindications. Treasure Island (FL): StatPearls Publishing, 2019.

25. English WJ, DeMaria EJ, Brethauer SA, et al. American Society for Metabolic and Bariatric Surgery estimation of metabolic and bariatric procedures performed in the United States in 2016. Surg Obes Relat Dis 2018;14:259-63.

26. Angrisani L, Santonicola A, Iovino P, et al. Bariatric Surgery and Endoluminal Procedures: IFSO Worldwide Survey 2014. Obes Surg 2017;27:2279-89.

27. Sjostrom L, Gummesson A, Sjostrom CD, et al. Effects of bariatric surgery on cancer incidence in obese patients in Sweden (Swedish Obese Subjects Study): a prospective, controlled intervention trial. Lancet Oncol 2009;10:653-62.

28. Schauer DP, Feigelson HS, Koebnick C, et al. Bariatric Surgery and the Risk of Cancer in a Large Multisite Cohort. Ann Surg 2019;269:95-101.

29. Adams TD, Stroup AM, Gress RE, et al. Cancer incidence and mortality after gastric bypass surgery. Obesity (Silver Spring) 2009; 17:796-802.

30. Adams TD, Hunt SC. Cancer and obesity: effect of bariatric surgery. World J Surg 2009;33:2028-33.

31. Ostlund MP, Lu Y, Lagergren J. Risk of obesity-related cancer after obesity surgery in a population-based cohort study. Ann Surg 2010;252:972-6.

32. Aravani A, Downing A, Thomas JD, et al. Obesity surgery and risk of colorectal and other obesity-related cancers: An English population-based cohort study. Cancer Epidemiol 2018;53:99-104.

33. Christou NV, Lieberman M, Sampalis F, et al. Bariatric surgery reduces cancer risk in morbidly obese patients. Surg Obes Relat Dis 2008;4:691-5.

34. Ward KK, Roncancio AM, Shah NR, et al. Bariatric surgery decreases the risk of uterine malignancy. Gynecol Oncol 2014;133:63-6.

35. Tee MC, Cao Y, Warnock GL, et al. Effect of bariatric surgery on oncologic outcomes: a systematic review and meta-analysis. Surg Endosc 2013;27:4449-56.

36. Mackenzie H, Markar SR, Askari A, et al. Obesity surgery and risk of cancer. Br J Surg 2018;105:1650-7.

37. Schauer DP, Feigelson HS, Koebnick C, et al. Association Between Weight Loss and the Risk of Cancer after Bariatric Surgery. Obesity (Silver Spring) 2017;25 Suppl 2:S52-7.

38. Adams TD, Gress RE, Smith SC, et al. Long-term mortality after gastric bypass surgery. N Engl J Med 2007;357:753-61.

39. Derogar M, Hull MA, Kant P, et al. Increased risk of colorectal cancer after obesity surgery. Ann Surg 2013;258:983-8.

40. Tao W, Konings P, Hull MA, et al. Colorectal Cancer Prognosis Following Obesity Surgery in a PopulationBased Cohort Study. Obes Surg 2017;27:1233-9.

41. Demierre MF, Higgins PD, Gruber SB, et al. Statins and cancer prevention. Nat Rev Cancer 2005;5:930-42.

42. Karp I, Behlouli H, Lelorier J, et al. Statins and cancer risk. Am J Med 2008;121:302-9.

43. Renehan AG. Bariatric surgery, weight reduction, and cancer prevention. Lancet Oncol 2009;10:640-1.

44. Hull MA, Markar SR, Morris EJA. Cancer risk after bariatric surgery - is colorectal cancer a special case? Nat Rev Gastroenterol Hepatol 2018;15:653-4.

45. El Ghoch M, Calugi S, Dalle Grave R. Increased Risk of Colorectal Cancer After Obesity Surgery. Ann Surg 2015;262:e15.

46. Raptis DA, Bachler T, Nocito A, et al. Obesity Surgery and the Risk of Colorectal Carcinoma-Searching for the Fly in the Ointment? Ann Surg 2017;265:e29-30.

47. Hull M, Lagergren J. Obesity and colorectal cancer. Gut 2014;63:205.

48. Backhed F, Ding H, Wang T, et al. The gut microbiota as an environmental factor that regulates fat storage. Proc Natl Acad Sci U S A 2004;101:15718-23.

49. Gopalakrishnan V, Spencer CN, Nezi L, et al. Gut microbiome modulates response to anti-PD-1 immunotherapy in melanoma patients. Science 2018;359:97-103.

50. Zitvogel L, Ma Y, Raoult D, et al. The microbiome in cancer immunotherapy: Diagnostic tools and therapeutic strategies. Science 2018;359:1366-70.

51. Le Chatelier E, Nielsen T, Qin J, et al. Richness of human gut microbiome correlates with metabolic markers. Nature 2013;500:541-6.

52. Li JV, Ashrafian H, Bueter M, et al. Metabolic surgery 
profoundly influences gut microbial-host metabolic crosstalk. Gut 2011;60:1214-23.

53. Liu R, Hong J, Xu X, et al. Gut microbiome and serum metabolome alterations in obesity and after weight-loss intervention. Nat Med 2017;23:859-68.

54. Sainsbury A, Goodlad RA, Perry SL, et al. Increased colorectal epithelial cell proliferation and crypt fission associated with obesity and roux-en-Y gastric bypass. Cancer Epidemiol Biomarkers Prev 2008;17:1401-10.

55. Song M, Garrett WS, Chan AT. Nutrients, foods, and colorectal cancer prevention. Gastroenterology 2015;148:1244-60.e16.

56. Song $M$, Wu K, Meyerhardt JA, et al. Fiber Intake and Survival After Colorectal Cancer Diagnosis. JAMA Oncol 2018;4:71-9.

57. Philip EJ, Torghabeh MH, Strain GW. Bariatric surgery in cancer survivorship: does a history of cancer affect weight loss outcomes? Surg Obes Relat Dis 2015;11:1105-8.

58. Demark-Wahnefried W, Platz EA, Ligibel JA, et al. The role of obesity in cancer survival and recurrence. Cancer Epidemiol Biomarkers Prev 2012;21:1244-59.

59. Dieli-Conwright CM, Lee K, Kiwata JL. Reducing the Risk of Breast Cancer Recurrence: an Evaluation of the Effects and Mechanisms of Diet and Exercise. Curr Breast Cancer Rep 2016;8:139-50.

60. Calle EE, Rodriguez C, Walker-Thurmond K, et al. Overweight, obesity, and mortality from cancer in a prospectively studied cohort of U.S. adults. N Engl J Med 2003;348:1625-38.

Cite this article as: Bruno DS, Berger NA. Impact of bariatric surgery on cancer risk reduction. Ann Transl Med 2020;8(Suppl 1):S13. doi: 10.21037/atm.2019.09.26
61. Ogden CL, Carroll MD, Fryar CD, et al. Prevalence of Obesity Among Adults and Youth: United States, 20112014. NCHS Data Brief 2015;(219):1-8.

62. Blixen CE, Singh A, Xu M, et al. What women want: understanding obesity and preferences for primary care weight reduction interventions among African-American and Caucasian women. J Natl Med Assoc 2006;98:1160-70.

63. Lynch CS, Chang JC, Ford AF, et al. Obese AfricanAmerican women's perspectives on weight loss and bariatric surgery. J Gen Intern Med 2007;22:908-14.

64. Wee CC, Davis RB, Huskey KW, et al. Quality of life among obese patients seeking weight loss surgery: the importance of obesity-related social stigma and functional status. J Gen Intern Med 2013;28:231-8.

65. Anderson WA, Greene GW, Forse RA, et al. Weight loss and health outcomes in African Americans and whites after gastric bypass surgery. Obesity (Silver Spring) 2007;15:1455-63.

66. Onyewu SC, Ogundimu OO, Ortega G, et al. Bariatric surgery outcomes in black patients with super morbid obesity: a 1-year postoperative review. Am J Surg 2017;213:64-8.

67. MacKintosh ML, Derbyshire AE, McVey RJ, et al. The impact of obesity and bariatric surgery on circulating and tissue biomarkers of endometrial cancer risk. Int J Cancer 2019;144:641-50.

68. Kant P, Hull MA. Excess body weight and obesity--the link with gastrointestinal and hepatobiliary cancer. Nat Rev Gastroenterol Hepatol 2011;8:224-38. 